\title{
SOROTIPOS DE Salmonella ISOLADOS EM UMA PROPRIEDADE DE SUÍNOS DE TERMINAÇÃO NO SUL DO BRASIL
}

\author{
Salmonella SEROTYPES ISOLATED FROM A FINISHING SWINE FARM \\ IN THE SOUTH OF BRAZIL
}

\section{Geovana Brenner Michael ${ }^{1}$ Rosalis Simoneti ${ }^{2}$ Marisa Ribeiro de Itapema Cardoso ${ }^{3}$ Marisa da Costa ${ }^{4}$}

\section{- NOTA -}

RESUMO

Em uma granja de suínos, foram isolados quinze sorotipos diferentes de Salmonella. Dois dos sorotipos isolados, Mbandaka e Tennessee, foram também encontrados na ração fornecida aos animais. Este estudo demonstrou a diversidade de sorotipos que podem estar presentes em uma granja e a necessidade de um melhor entendimento da epidemiologia da infecção por Salmonella.

Palavras-chave: Salmonella, sorotipos, suínos.

\section{SUMMARY}

Fifteen different serovars of Salmonella were isolated from a swine farm, two of the isolated serovars, Mbandaka and Tennessee, were also found in the feed supplied to the animals. This study demonstrated the diversity of serovars that could occur in a farm and the need of a better understanding on epidemiology of Salmonella infection.

Key words: Salmonella, serovars, swines.

A presença de Salmonella em suínos pode representar um risco para a saúde pública, uma vez que o aumento do número de toxinfecções devido ao consumo de produtos suínos contaminados tem sido observado em diversos países. Com o esclarecimento dos fatores de risco e formas de entrada do microrganismo na granja, será possível traçar estratégias para programas de controle, que diminuam o índice de portadores ao abate. Entretanto, a diversidade de fontes de isolamento de Salmonella na granja, bem como a variedade de sorotipos nela isolados têm dificultado estas pesquisas (DAVIES \& FUNK, 1999). No presente estudo, partindo de uma propriedade na qual havia um surto de infecção por Salmonella, buscou-se determinar o perfil de sorotipos presentes nos suínos infectados e na ração fornecida aos animais.

A propriedade, localizada na região do Vale do Taquari, Rio Grande do Sul, alojava 359 suínos, em fase de terminação, distribuídos em 30 baias. Os animais apresentavam-se clinicamente normais. Foram realizadas duas visitas na granja, com intervalo de 40 dias, sendo amostrado o mesmo lote de animais nas duas ocasiões. $\mathrm{Na}$ primeira visita, foram sorteadas 21 baias, sendo amostrados 5

\footnotetext{
${ }^{1}$ Farmacêutico Bioquímico, Mestre, Professor Substituto, Instituto de Ciências Básicas da Saúde, ICBS, Universidade Federal do Rio Grande do Sul (UFRGS).

${ }^{2}$ Médico Veterinário.

${ }^{3}$ Professor Titular, Departamento de Medicina Veterinária Preventiva, Faculdade de Veterinária, UFRGS, Av. Bento Gonçalves, 9090 , 90140-000, Porto Alegre, RS, Brasil. E-mail: mcardoso@ vortex.ufrgs.br. Autor para correspondência

${ }^{4}$ Professoro Adjunto, Instituto de Ciências Básicas da Saúde, ICBS, UFRGS.
} 
animais/baia/visita. Na segunda visita, os animais das mesmas baias foram amostrados, sendo coletados, em cada visita, amostras de ração, fezes individuais dos suínos $(\mathrm{n}=105)$ e fezes de lote $(n=21)$. Entende-se por fezes de lote aquelas que estão depositadas no chão e correspondem à mistura de fezes de vários animais. Cada amostra $(25 \mathrm{~g})$ foi semeada, após o pré-enriquecimento em Água Peptonada Tamponada $\left(37^{\circ} \mathrm{C} / 24 \mathrm{~h}\right)$, em caldo Tetrationato Müller-Kauffmann (Difco) e caldo Rappaport-Vassiliadis (Merck). Após incubação $\left(42^{\circ} \mathrm{C} / 24 \mathrm{~h}\right)$, alíquotas dos caldos foram semeados em meios sólidos seletivos (XLT4 e Verde Brilhante, Merck). As colônias suspeitas foram identificadas conforme HOLT et al. (1994). Colônias confirmadas como Salmonella sp. foram selecionadas para sorotipagem no Instituto Oswaldo Cruz.

$\mathrm{Na}$ coleta realizada na primeira visita, 53 animais $(50,4 \%)$ foram positivos. Em todas as 21 baias coletadas, pelo menos um animal era positivo, sendo que em uma delas todos os 5 animais coletados excretavam Salmonella. Nas fezes de lote,

Tabela 1 - Sorotipos de Salmonella sp. isolados em duas coletas, a partir de fezes de lote e individualmente coletadas de suínos em uma propriedade de terminação, no Rio Grande do Sul.

\begin{tabular}{|c|c|c|c|c|c|}
\hline \multirow{3}{*}{ Baia } & \multicolumn{3}{|c|}{$1^{\circ}$ Coleta de fezes } & \multirow{2}{*}{\multicolumn{2}{|c|}{$\frac{2^{\circ} \text { Coleta de fezes }}{\text { Individual }}$}} \\
\hline & Lote $^{1}$ & & Individual $^{2}$ & & \\
\hline & Sorotipos & $n^{3}$ & Sorotipos & $\mathrm{n}$ & Sorotipos \\
\hline 1 & Anatum & 2 & Orion & -5 & - \\
\hline 2 & $\mathrm{ND}^{4}$ & 2 & Typhimurium, Tennessee & - & - \\
\hline 3 & ND & 3 & Heidelberg & 1 & Heidelberg \\
\hline 4 & ND & 3 & Typhimurium & - & - \\
\hline 5 & ND & 2 & Lexington, Tennessee & - & - \\
\hline 6 & ND & 2 & Tennessee & - & - \\
\hline 7 & Typhimurium & 3 & ND & - & - \\
\hline 8 & ND & 3 & Rissen $(3)^{6}$ & 1 & S. $\operatorname{sp}(4,5:-: 11,2)$ \\
\hline 9 & ND & 5 & $\begin{array}{c}\text { Infantis, Mbandaka, } \\
\text { Thyphimurium }\end{array}$ & - & - \\
\hline 10 & ND & 3 & Grupensis (2), Minnesota & - & - \\
\hline 11 & - & 1 & Mbandaka & 2 & Typhimurium \\
\hline 12 & - & 3 & Mbandaka, Rissen & - & - \\
\hline 13 & ND & 2 & Grupensis & - & - \\
\hline 14 & - & 2 & Montevideo (2) & 1 & Typhimurium \\
\hline 15 & - & 2 & Cerro, Orion & - & - \\
\hline 16 & Anatum & 2 & Anatum & 1 & Cerro \\
\hline 17 & ND & 4 & Cerro, Typhimurium & - & - \\
\hline 18 & ND & 3 & Mbandaka, Tennessee (2) & 1 & Montivideo \\
\hline 19 & Mbandaka (2) & 1 & ND & - & - \\
\hline 20 & - & 1 & Agona & - & - \\
\hline 21 & - & 4 & Anatum & - & - \\
\hline
\end{tabular}

${ }^{1}$ Fezes de lote $;{ }^{2}$ Fezes coletadas individualmente; ${ }^{3}$ número de animais positivos; ${ }^{4}$ sorotipos não determinados; ${ }^{5}$ não houve isolamento; ${ }^{6}$ números entre parênteses correspondem ao número de amostras identificadas como pertencente ao respectivo sorotipo. este microrganismo foi detectado em 14 das 21 baias coletadas (Tabela 1). A amostra de ração também foi positiva, tendo sido uma provável fonte de contaminação. Na segunda coleta, houve uma diminuição do número de animais positivos; apenas 7 animais $(6,6 \%)$, distribuídos em 6 baias estavam excretando Salmonella. Nesta coleta, não foi possível detectar a bactéria nas fezes de lote nem na ração. A diminuição do número de animais positivos, aliada ao resultado negativo da ração, pode indicar que muitos animais amostrados na primeira visita estavam excretando Salmonella como portadores passivos ou tornaram-se portadores latentes. Apesar de existirem 6,6\% de animais excretando a bactéria, além de um número imprevisível de animais portadores latentes, nenhuma das amostras de fezes de lote foi positiva. Esta discrepância entre fezes de lote e presença de animais portadores já havia sido observada por WEISS et al. (1999), indicando que este tipo de amostra só será eficiente em lotes onde esteja ocorrendo um alto nível de excreção de Salmonella.

De 652 colônias confirmadas como Salmonella, 50 foram sorotipadas, e então classificadas em 15 sorotipos. Na primeira coleta, foram identificados os sorotipo Mbandaka e Tennessee na ração, os quais foram encontrados nas fezes coletadas individualmente, e nas fezes de lote (sorotipo Mbandaka). Nenhum destes sorotipos foi identificado na segunda coleta. Os sorotipos Cerro, Heidelberg, Montevideo e Typhimurium foram encontrados nas fezes de animais em ambas coletas (Tabela 1).

Como no presente estudo somente uma parcela das colônias de Salmonella isoladas foi antigenicamente caracterizada, não é possível identificar os sorotipos predominantes nas diferentes amostras. Da mesma forma, não é possível concluir que a ração contaminada tenha sido a única fonte de contaminação do lote, uma vez que apenas 2/15 sorotipos foram encontrados na mesma. BAGGESEN et al. (1997) compararam os sorotipos de Salmonella isolados a partir de ração, rebanho suíno, carcaças e humanos. Foi observada uma grande variação na capacidade dos diferentes sorotipos de Salmonella em serem transmitidos na cadeia de produção de alimentos e em causarem doença no homem. Os fatores que influenciam nesta capacidade, por sua vez, ainda não estão completamente determinados. 
A diversidade de sorotipos isolados e a variação no nível de excreção, observadas ao longo do período de terminação nos animais amostrados no presente estudo, reforçam a importância da determinação da epidemiologia da infecção por Salmonella em rebanhos suínos.

\section{REFERÊNCIAS BIBLIOGRÁFICAS}

BAGGESEN, D.L., SORENSEN, L.L., KRAUSER, M., $\boldsymbol{e}$ t al. The occurence of Salmonella enterica serotypes in animal feed, pig, pork and man. In: INTERNATIONAL SYMPOSIUM ON EPIDEMIOLOGY AND CONTROL OF Salmonella IN PORK, 2, 1997, Copenhagen. Anais.. Copenhagen : [S.n], 1997. p.56-59.
DAVIES, P.R., FUNK, J.A. Epidemiology and control of Salmonella in pork - some of questions. In: SYMPOSIUM ON THE EPIDEMIOLOGY AND CONTROL OF Salmonella IN PORK, 3, 1999, Washington. Anais... Washington.[S.n.], 1999. p.1-11.

HOLT, J.G., KRIEG, N.R., SNEATH, P.H.A., et al. (Eds.). Bergey's manual of determinative bacteriology. 9.ed. Baltimore : Williams \& Wilkins, 1994. Cap.5: Facultative anaerobic Gram-negative rods: p.175-189.

WEISS, L.H.N., NONNIG, R., CARDOSO, M.R.I., et al. Occurence of Salmonella in finishing pigs in south Brazil. In: INTERNATIONAL SYMPOSIUM ON EPIDEMIOLOGY AND CONTROL OF Salmonella IN PORK, 3, 1999, Washington. Anais... Washington : [S.n.], 1999. p.184. 